\title{
Teología política y Modernidad: Peterson, Blumenberg y Schmitt
}

\author{
Political Theology and Modernity: \\ Peterson, Blumenberg and Schmitt
}

ROBERTO NAVARRETE ALONSO*

\begin{abstract}
Resumen: El presente artículo trata de dilucidar el significado del sintagma «teología política» en el pensamiento de C. Schmitt conforme a lo postulado por éste en su homónima doctrina de la soberanía. Para ello se tendrán en cuenta las negaciones teológica (Peterson) y científico-filosófica (Blumenberg) de la propuesta schmittiana, así como la respuesta dada por Schmitt a ambas en Teología política II. Tratará de mostrarse así que la teoría schmittiana de la secularización, tal y como ésta fue postulada en 1922, no lleva a cabo una teologización de la política sino que, por el contrario, presupone la muerte de Dios y, en este sentido, afirma la secularidad intrínseca de la Modernidad.

Palabras clave: Peterson, Blumenberg, Schmitt, Modernidad, teología política, secularización.
\end{abstract}

\begin{abstract}
The aim of this paper is to clarify the meaning of Schmitt's expression «political theology» by discussing the homonymous Schmittian doctrine of sovereignty. I will evaluate, on the one hand, the theological (Peterson) and the scientific-philosophical (Blumenberg) critiques of Schmitt and, on the other hand, Schmitt's answer to both critiques, which can be found in Political Theology II. I will try to prove that Schmitt's theory of secularization, as it was proposed in 1922, does not imply a theologization of politics. On the contrary, this theory presupposes the death of God and, therefore, it states that secularity is intrinsic to Modern Age.
\end{abstract}

Key words: Peterson, Blumenberg, Schmitt, Modernity, Political Theology, Secularization.

La obra sobre El monoteísmo como problema político de Erik Peterson tuvo un doble propósito. De una parte, como indica su subtítulo, Ein Beitrag zur Geschichte der politischen Theologie im Imperium Romanum, ofrece una erudita aproximación histórica al problema teológico-político en la Antigüedad. Por otro lado, constituye de manera implícita una

Fecha de recepción: 04/07/2013. Fecha de aceptación definitiva: 10/12/2013.

* Doctor en Filosofía (Universidad Autónoma de Madrid). Líneas de investigación: Carl Schmitt; Franz Rosenzweig; teología política; concepto de secularización; concepciones del tiempos histórico; pensamiento hebreo contemporáneo. Publicaciones recientes: edición de Rosenzweig, F., Escritos sobre la guerra, Sígueme, Salamanca, 2015; coedición (junto a V. Rocco) del volumen colectivo Teología y teonomía de la política, Abada, Madrid, 2012; «En el principio no había (la) ley. De la especificidad política del Dasein judío», en: V. Rocco - R. Navarrete (eds.), Teología y teonomía de la política, Abada, Madrid, 2012, pp. 221-234; y «Europa en Turquía, y viceversa. Una aproximación desde la geo(teo)política de la historia», en: V. Rocco - D. S. Garrocho (eds.), Europa: tradición o proyecto, Abada, Madrid, 2013, pp. 69-92. Correo electrónico: roberto.navarrete.alonso@gmail.com. 
denuncia del compromiso nacionalsocialista de Carl Schmitt así como la articulación de las bases teológicas de una resistencia frente al totalitarismo a partir del retorno a la doctrina de las dos ciudades de San Agustín, presente en la exposición petersoniana desde la primera página $^{1}$. Esta crítica política apenas fue percibida por el acusado. La única alusión directa de Peterson a Schmitt y su teología política está revestida no en vano de carácter científico. Es a ella y no a la velada acusación política personal que el jurista responde en Teología política $I^{2}$.

El hecho de que el presente trabajo se refiera a la polémica mantenida por Schmitt con Peterson antes de abordar el debate entre Hans Blumenberg y el jurista alemán se justifica en primer lugar por razones cronológicas. Aunque Schmitt respondió a ambos autores en 1970, lo cierto es que la crítica de Peterson data de 1935. La de Blumenberg, Die Legitimität der Neuzeit, vio la luz en 1966, aunque el debate entre ambos se inauguró realmente en 1962, con ocasión de la séptima edición del Deutscher Kongreß für Philosophie ${ }^{3}$. Por otro lado, el orden de la exposición responde al hecho de que la réplica de Schmitt se dirige principalmente contra las conclusiones alcanzadas por Peterson y sólo en su «Epílogo» se enfrenta a la defensa blumenberguiana de la legitimidad moderna ${ }^{4}$. Por último, desde un punto de vista netamente argumentativo, la respuesta de Schmitt a Peterson implica la distinción entre los diversos sentidos de teología política que están en juego y, así, aclara y determina la posición del jurista en su enfrentamiento con Blumenberg a propósito de la categoría de «secularización».

\section{La leyenda de la liquidación de la teología política}

Conforme a la argumentación petersoniana, el monoteísmo como problema político habría surgido en el cristianismo como consecuencia de la elaboración helenística de la fe judía en el Dios único inaugurada por Filón de Alejandría y proseguida por los apologetas cristianos Justino, Taciano y Teófilo de Antioquía, es decir, de la conjunción del principio monoteísta hebreo y del principio monárquico de la filosofía griega y, concretamente, de la de Aristóteles, que cierra el Libro XII de su Metafísica con las siguientes palabras de Homero (Ilíada II, v. 204): «No es cosa buena el mando de muchos: uno solo debe ejercer el mando»5.

1 Cf. Peterson, E., El monoteísmo como problema político [MPP], trad. de A. Andreu, Madrid, Trotta, 1999 , p. 50.

2 Cf. Schmitt, C., «Teología política II. La leyenda de la liquidación de toda teología política» [TPII], en: Teología política, trad. de J. Navarro Pérez, Madrid, Trotta, 2009, pp. 59-133. Sobre el debate entre Peterson y Schmitt, cf. Géreby, G., «Political Theology versus Theological Politics: Erik Peterson and Carl Schmitt», New German Critique (Durham), $\mathrm{n}^{\circ}$ 105, 2008, pp. 7-33.

3 Cf. Blumenberg, H., «,Säkularisation”. Kritik einer Kategorie historischer Illegitimität», en: H. Kuhn - F. Wiedmann (eds.), Die Philosophie und die Frage nach dem Fortschritt, München, Pustet, 1964, pp. 240-265 e Id., «Secularización. Crítica de una categoría de injusticia histórica», en: La legitimación de la Edad Moderna [LEM], trad. de P. Madrigal, Valencia, Pre-textos, 2008, pp. 11-120.

4 Cf. Schmitt, C., «Epílogo. Situación actual del problema: la legitimidad de la Edad Moderna», en: TPII, 123133. A raíz de esta respuesta, Blumenberg introdujo una serie de cambios en la primera parte del texto de 1966 que vieron la luz en 1974 bajo el título Säkularisierung und Selbstbehauptung y se introdujeron en una nueva versión de Die Legitimität der Neuzeit en 1988. La traducción de ésta al castellano, obra de P. Madrigal, es la versión empleada en este trabajo.

5 Ar. Metaph., XII, 10, 1076a. 
La ideología resultante, es decir, el concepto político-teológico de la monarquía divina, es a su vez resumido por Peterson en la fórmula teológico-política «un dios, un rey». Tanto el judaísmo como el cristianismo primitivo usaron este eslogan teológico-político, según el teólogo, para defender su superioridad religiosa sobre el politeísmo pagano. Éste legitimaba teológicamente el funcionamiento jurídico del Imperio, esto es, el hecho de que en él fuesen toleradas las particularidades nacionales de acuerdo con la idea resumida en la expresión Le roi règne mais il ne gouverne pas. La rebelión metafísica del monoteísmo cristiano era al mismo tiempo una rebelión política: una subversión contra las particularidades nacionales en que se fundaba el orden del Imperio. A diferencia del caso de los cultos nacionales e incluso del judaísmo, Roma necesitó de la persecución del cristianismo como religio illicita.

La respuesta cristiana consistió, según Peterson, en una interpretación del problema político del Imperium Romanum y de la Pax Augusta a la luz de la escatología cristiana, es decir, en el establecimiento de una relación providencial entre el fin del «Estado nacional» por la monarquía de Augusto y la aparición de Cristo. Tal habría sido la posición de los arrianos Orígenes, Eusebio de Cesarea u Orosio, quienes habrían empleado esta reunión conceptual de paz, monoteísmo y monarquía para justificar teológicamente la política de Augusto y Constantino: en correspondencia con el único monarca en el cielo, debía haber un único monarca en la tierra.

Esta posición se habría visto debilitada, continúa Peterson, por motivos teológicos y políticos. Primero, por una circunstancia política fundamental: las sacudidas a las que estuvo sometido el Imperio durante el siglo V, es decir, la puesta en cuestión de la Pax Romana -y con ella de su relación con la escatología- de la que da testimonio San Agustín en De civitate Dei ${ }^{6}$. Segundo, por el establecimiento del dogma de la Trinidad: si el concepto arriano de unidad divina se ponía en cuestión, la unidad del Imperio quedaba teológicamente deslegitimada. Tal fue el resultado del Concilio de Nicea (325), que censuró el arrianismo como herejía. De acuerdo con Peterson, con ello quedaba probada la imposibilidad teológica de toda teología política rigurosamente cristiana, incluida aquella cuyo concepto había introducido Schmitt en su Teología política ${ }^{7}$. Como se indicó más arriba, sin embargo, la crítica de Peterson a Schmitt no se reduce a este aspecto científico sino que contiene de manera implícita un alcance político. Su liquidación de la teología política arriana de Eusebio de Cesarea establece de manera velada un paralelismo histórico entre ella y la teología política de Schmitt, es decir, entre el totalitarismo nacionalsocialista y el cesaropapismo de Constantino. El jurista es denunciado, por lo tanto, como teólogo del III Reich. Peterson, por su parte, se presenta a sí mismo como un nuevo San Agustín. Si el santo de Hipona se enfrentó a los teólogos imperiales romanos, el teólogo de Hamburgo hace lo propio con Schmitt, siquiera de manera encubierta.

De entre los momentos en los que cabe entrever esta crítica del compromiso político de Schmitt con el nacionalsocialismo, el jurista sólo se hará cargo de la acusación más general, es decir, del paralelismo entre el totalitarismo de A. Hitler y el cesaropapismo de Constan-

6 Aug., Сiu., III, 30 у MPP, 93.

7 El teólogo alude explícitamente al jurista en la siguiente nota a pie de página: «El concepto de teología política fue introducido en la literatura por Carl Schmitt, Politische Theologie, München, 1922. Pero no propuso sistemáticamente aquellas cortas argumentaciones. Nosotros hemos intentado aquí probar con un ejemplo concreto la imposibilidad teológica de una "teología política"» (MPP, 95, nt. 221). 
tino, sugerido a partir de la identificación de los conceptos de Monarch y Führer, así como en el Motto del tratado ${ }^{8}$. No obstante, Schmitt no lo entendió como una crítica ad personam sino como parte de la argumentación científica petersoniana, a la manera de una reivindicación de la actualidad del monoteísmo como problema político en 1935. Fue Jacob Taubes quien llamó la atención del jurista sobre lo que él considera un mensaje oculto de Peterson, dirigido directamente contra Schmitt por su implicación en el diseño de la estructura jurídica del III Reich o, en otros términos, por su supuesta legitimación teológico-política del nacionalsocialismo9 . Fuese Schmitt consciente o no de esta acusación, Teología política II constituye una respuesta por alusiones, a lo menos, científicas. La réplica se dirige contra la relación establecida entre la argumentación y la conclusión, es decir, contra la tesis misma de Peterson. Ésta, consecuentemente, no es aceptada como res judicata sino sometida a un examen crítico por razones de exactitud científica: a fin de evitar precisamente la creación de leyendas que, al contrario de lo que propiamente significa el término, no se leen sino que únicamente se citan ${ }^{10}$.

A juicio de Schmitt, cuya opinión se suscribe aquí, la exposición de Peterson adolece de una triple limitación: histórica, teológica y conceptual (teórico-política). Así, una primera debilidad básica consiste en el desequilibro existente entre la documentación que ofrece a manera de prueba y la conclusión que extrae del material probatorio. La labor historiográfica del erudito teólogo alemán está restringida a los primeros siglos cristianos y, en concreto, a la relación de Eusebio de Cesarea con Constantino, mientras que la conclusión ofrece un veredicto global sobre cualquier teología política. Esta limitación histórica del trabajo de Peterson es a su vez índice de una limitación teológica. El examen petersoniano del monoteísmo excluye por lo pronto al dios de Mahoma, atendiendo únicamente a los monoteísmos hebreo, pagano y cristiano-trinitario, así como concediendo a éste, en exclusiva, la posibilidad de una teología propiamente dicha. En efecto, Peterson opera en función de una delimitación muy clara del significado del propio concepto de teología, establecida por él mismo en el ensayo Was ist Theologie? ${ }^{11}$. Según éste, la teología se refiere a la extensión de la revelación del Verbo en forma de una argumentación concreta y, por tanto, tiene un carácter específicamente cristiano -en particular, cristiano-trinitario-.

El dogma de la Trinidad tal y como fue establecido en el Concilio de Nicea en respuesta a la controversia arriana es utilizado por Peterson para declarar imposible sin más toda teología política, excepción hecha de los monoteísmos no cristiano-trinitarios. Teología política y teología cristiana stricto sensu se excluyen en la exposición de Peterson de un modo tal que cuando éste observa algo semejante a una teología política en los primeros autores cristianos lo atribuye necesariamente a influencias judías o paganas, es decir, herejes. A juicio de Peterson, toda teología política supone un abandono de la ortodoxia teológica mientras que ésta, la teología propiamente dicha, se mantiene por definición al margen de

8 Respecto de lo primero, cf. MPP, 70. El lema está extraído de De vera religione 45, 84 de San Agustín y reza: «Tiene la soberbia cierto apetito de unidad y de omnipotencia, pero en la soberanía de las cosas temporales, que pasan todas como sombra». La respuesta de Schmitt a ambas cuestiones se encuentra en TPII, 65-66.

9 Cf. Taubes, J., «Carta a Carl Schmitt», en: La teología política de Pablo, trad. de M. García-Baró, Madrid, Trotta, 2007, pp. 181-184.

10 Cf. TPII, 64-65.

11 Cf. Peterson, E., «Was ist Theologie? (1925)», en: Theologische Traktate, München, Koesel, 1951, pp. 9-43. 
todo posicionamiento político. La argumentación del teólogo, como señala el jurista, exigiría sin embargo ir acompañada de un ejemplo positivo de teología trinitaria apolítica tomado de la misma época. Sin embargo, carece de él ${ }^{12}$.

Por último, al margen de su limitación histórica o, si se quiere, lo anacrónico de una argumentación que disfrazaba una crítica al Führerprinzip y al sistema monopartidista del totalitarismo nacionalsocialista, así como de la restrictiva identificación de «teología» y «teología cristiano-trinitaria», la exposición petersoniana adolece de una limitación conceptual esencial: la exclusión de cualquier forma de unidad política no monárquica, es decir, la restricción del planteamiento político al problema de la monarquía como límite supuestamente impuesto por la noción de monoteísmo. Según Schmitt, el problema teológico-político está mal planteado por su crítico: el concepto central sistemáticamente correcto en torno al cual debe orientarse la cuestión teológico-política no debe ser «monarquía» ni cualquier otra forma de gobierno, sino el concepto de «unidad política» y el modo en que ésta se (re) presenta. De la fórmula «un dios» no se sigue necesariamente «un rey» sino que admite «un pueblo»y, por lo tanto, la posibilidad de la democracia ${ }^{13}$.

\section{Sentidos de «teología política»}

La exposición de las limitaciones histórica, teológica y conceptual o teórico-política del planteamiento petersoniano permite a Schmitt poner de manifiesto la existencia de un desequilibrio entre la argumentación y la conclusión pretendidamente obtenida por el teólogo alemán. Ésta aparece así como una exageración conceptual, una leyenda condicionada política e históricamente. Según Schmitt, la liquidación de la teología política llevada a cabo por Peterson alcanza a lo sumo la liquidación de un prototipo, el del cesaropapismo de Eusebio de Cesarea, con el que el teólogo identificaba a su propio enemigo: el culto al líder propio de la legitimidad carismática en que se fundamenta el totalitarismo.

La acusación dirigida por Peterson hacia el adalid de la teología política, que supuestamente abusaba de la revelación cristiana para justificar una determinada situación política, se vuelve contra el propio acusador. El desequilibrio entre el material probatorio y la conclusión es consecuencia de la determinación de la exposición en función del escenario político alemán del momento. Es precisamente esta circunstancia la que obligó a Peterson a considerar la cuestión de la legitimidad carismática como una categoría carente de toda relación significativa con la teología propiamente dicha, estableciendo así una equiparación interesada de la legitimidad carismática del líder y la legitimidad dinástico-hereditaria del monarca, es decir, de las respectivas legitimidades de los apóstoles Pablo y Pedro que el propio Peterson había distinguido en su tratado sobre la Iglesia ${ }^{14}$.

12 Cf. TPII, 99-100. San Atanasio, modelo de ortodoxia trinitaria pero enemigo acérrimo del arrianismo y hombre belicoso, señala Schmitt, no habría servido como tal ejemplo. A pesar de su carácter pretendidamente teológicodogmático, el propio Concilio de Nicea fue un acontecimiento cuya verdadera problemática, «la mezcla, que sólo se puede distinguir mediante institucionalizaciones precisas, de lo sagrado y lo mundano, del más allá y el más acá, de la teología y la política» (TPII, 100), es obviada por Peterson.

13 Cf. TPII, 91.

14 Cf. TPII, 87-88 y Peterson, E., «Die Kirche (1929)», en: Theologische Traktate, op. cit., pp. 417 ss. Sobre los tipos de legitimidad o dominación (Herrschaft), cf. Weber, M., Economía y sociedad. Esbozo de sociología 
Schmitt somete a examen la conclusión en cuestión, la liquidación teológica de toda teología política, en el último capítulo de su Teología política II. En él salen a la luz los distintos sentidos del sintagma «teología política»y, en concreto, el propio modo en que lo concibe el jurista, que distingue analíticamente las tres afirmaciones que conforman la conclusión del teólogo: en primer lugar, que el fracaso de la monarquía divina se debe a la instauración del dogma de la Trinidad; en segundo lugar, que la subsiguiente liquidación teológica (cristiano-trinitaria) del monoteísmo como problema político operó una ruptura fundamental con toda teología política que hiciera un uso impropio de la revelación cristiana para justificar un determinado statu quo, es decir, que «teología» y «teología política» se excluyen mutuamente; por último, que sólo en el ámbito del judaísmo o del paganismo puede darse algo parecido a una teología política ${ }^{15}$.

Los tres asertos enumerados operan una negación teológica de la teología política a partir de la teología de una religión trinitario-monoteísta entendida en términos absolutos. Esta liquidación cristiano-trinitaria del monoteísmo como problema político es, a pesar de su contundencia y carácter pretendidamente definitivo, ambigua. Puede dar lugar a malentendidos. Schmitt distingue por lo pronto dos interpretaciones posibles de la conclusión petersoniana. De una parte, puede significar que el monoteísmo es un problema político, no teológico. De otra, que la teología puede juzgar y ha liquidado el problema político del monoteísmo en tanto que res mixta: materia tanto de la teología como de la política.

Conforme al primer punto de vista se entiende por «teología», como pretende Peterson, una teología pura, apolítica, que por definición no podría ser capaz de emitir juicio alguno sobre algo específicamente político. La segunda interpretación, en cambio, debe necesariamente contemplar la posibilidad de que se lleve a cabo una evaluación política del asunto de acuerdo con la cual la propia liquidación teológica de un problema político significaría ya un fenómeno teológico-político. En este último sentido, la teología cuya pureza reivindica Peterson para liquidar toda teología política renunciaría precisamente a su carácter apolítico e inauguraría un conflicto de competencias: un conflicto político o una pugna entre instituciones y órdenes concretos (Estado e Iglesia). Adquiere así sentido la lacónica auto-descripción de Schmitt a propósito de su relación con el enemigo: «Yo soy jurista y no teólogo» ${ }^{16}$.

La formulación de la conclusión de Peterson habría disfrazado según Schmitt el problema por él abordado en 1922 y que resume a la perfección su tesis sobre la secularización: «Todos los conceptos centrales de la moderna teoría del Estado son conceptos teológicos secularizados» ${ }^{17}$. La cuestión no era, como reclamaba su crítico, la relación entre política y revelación sino, como aclara el jurista, aquella «entre teología y jurisprudencia como dos ciencias que en buena medida trabajan con conceptos compatibles estructuralmente» ${ }^{18}$. La

comprensiva, trad. de J. Medina Echavarría, México D.F., FCE, 1979, pp. 170-197 e Id., El político y el científico, trad. de F. Rubio Llorente, Madrid, Alianza, 1984, pp. 84-87.

15 Cf. TPII, 113 ss.

16 Schmitt, C., Ex captitivate salus. Experiencias de la época 1945-1947, trad. de A. Schmitt de Otero, Madrid, Trotta, 2010, p. 77.

17 Schmitt, C., «Teología política. Cuatro capítulos sobre la doctrina de la soberanía» [TP], en: Teología política, trad. de F. J. Conde, Madrid, Trotta, 2009, p. 37.

18 TPII, 115. 
liquidación petersoniana de la teología política se vuelve legendaria desde el momento en que el sintagma «teología política» no es concebido exclusiva y absolutamente desde un punto de vista teológico sino también desde uno científico, en el sentido de una Begriffsgeschichte.

Se distinguen de este modo al menos dos sentidos de «teología política», el teológico (Peterson) y el jurídico-político (Schmitt), que a su vez deben ser nítidamente distinguidos de una concepción confesional de la teología política, es decir, de la mera creencia en el desempeño divino de un papel político en el mundo. Tal modo de concebir las relaciones entre teología y política, sin identificarse con la concepción schmittiana, escaparía al igual que esta última del veredicto de Peterson, ya que poco o nada tiene que ver con la teología dogmática ${ }^{19}$. Toda vez que ésta no produce la fe sino que constituye más bien la sistematización de una fe dada de antemano, la liquidación teológica de la teología política no afecta a su sentido confesional. Algo muy semejante ocurre cuando la teología política es considerada desde un punto de vista institucional. Indisolublemente ligado al confesional en la medida en que la institución concreta que constituye la Iglesia cuenta entre sus miembros a feligreses legos en conocimientos teológicos, el sentido institucional de «teología política» se refiere a la condición ambigua de la propia Iglesia: el hecho de que, sin ser de este mundo, está en este mundo y no puede, por ello, alejarse definitivamente de él ni de la historia, es decir, de la política ${ }^{20}$.

Consciente de la peculiaridad de su propia época, no fueron los sentidos confesional e institucional aquellos que reivindicó el jurista Schmitt. La desteologización característica del siglo XX es el resultado de la evolución histórica posterior a la última gran irrupción del poder directo de la institución eclesiástica y, por cierto, no sólo de sus teólogos sino fundamentalmente de sus predicadores y feligreses: la Reforma. De la destrucción definitiva de la unidad de la Respublica Christiana medieval que supuso el éxito del protestantismo en al menos una parte de Europa, unida a la neutralización del conflicto religioso que propició la aparición del Estado nacional como nueva forma de unidad política, se siguió la sustracción del poder directo de la Iglesia por parte de cada uno de los Estados que conforman el pluriverso político de la Europa moderna. Ello no significa sin más que la teología política, en sus sentidos confesional e institucional, haya desaparecido, sino que tiene otras raíces y otros efectos. Dado que el poder político directo ha de ser detentado por el Estado, la Iglesia sólo puede aspirar al ejercicio de un poder indirecto, por ejemplo, mediante el establecimiento de acuerdos y la firma de tratados con las unidades políticas en las que se ubican y con las que necesariamente se relacionan. Del hecho de que las intenciones de dichos acuerdos no sean teológicas en el sentido de la constitución de verdades de fe y por lo tanto no caigan bajo el veredicto de Peterson, no se sigue que no tengan un evidente carácter teológico-político sin incurrir por ello en herejía ${ }^{21}$.

19 Cf. TPII, 101, Galindo Hervás, A., «Los fundamentos teológicos de la política moderna», Araucaria (Sevilla), año VI, no 12, Segundo semestre de 2004, pp. 41-47 e Id. «Teología política "versus" comunitarismo impolítico», Res Publica (Murcia), n 6, 2000, pp. 37-39.

20 Cf. TPII, 87.

21 Valdría aducir en este punto el Pacto de Laterano entre Italia y la Santa Sede (11 de febrero de 1929) o el Concordato entre la Santa Sede y España (27 de octubre de 1953), firmados ambos en nombre de la Santísima Trinidad. Sobre la distinción entre poder directo e indirecto, cf. Schmitt, C., «Diálogos sobre el poder y el acceso al poderoso», en: Diálogos, trad. de A. Schmitt de Otero, Madrid, Instituto de Estudios Políticos, 1962, pp. 70 ss. 
La liquidación de toda teología política pretendida por Peterson no afecta, por tanto, al sentido confesional e institucional de «teología política», pero tampoco a la relación entre teología y política que significa la tesis de Schmitt que inauguró el debate en 1922. La misma secularización que ha convertido en insignificante el sentido teológico de «teología política» y ha relegado a segundo plano sus sentidos confesional e institucional ofrece la clave para entender aquello a lo que se refiere un jurista y teórico del derecho como Schmitt con este polémico par de palabras.

\section{La crítica de Blumenberg al Säkularisationstheorem}

Dado el escaso interés por él mostrado en relación a la crítica blumenberguiana del «teorema de la secularización» (Säkularisationstheorem), a la que el autor de Teología política II dedica únicamente su «Epílogo», cabe suponer que la distinción anterior era suficiente a ojos de Schmitt para refutar también las objeciones planteadas por Blumenberg en La legitimidad de la Edad Moderna. En comparación con las de Peterson, éstas estaban dotadas sin embargo tanto de una mayor profundidad como de un mayor alcance, toda vez que no se referían únicamente a la doctrina schmittiana de la soberanía sino, más en general, al rendimiento teórico mismo de «secularización» como categoría genealógica de la Modernidad.

Blumenberg presenta en efecto una crítica al concepto originariamente jurídico de «secularización» en tanto en cuanto su ampliación metafórica más allá de su sentido originariamente jurídico, de acuerdo con la argumentación blumenberguiana, convierte dicho concepto en una categoría de injusticia histórica. No es por tanto la secularización en sí misma lo que se rechaza, sino el uso y abuso del servicio prestado por ella como argumento justificativo de la pregnancia del cristianismo en la Edad Moderna. Aunque su aplicabilidad histórica es a ojos Blumenberg indudable, de su rendimiento y operatividad tan sólo se sigue una evidencia contra cuya superficialidad no puede objetarse más que el hecho de que con el término «secularización» se dice prácticamente nada. Blumenberg propone por ello distinguir entre los usos descriptivo y explicativo del concepto a fin de contestar a la pregunta de si la categoría «secularización» explica verdaderamente la singularidad moderna de modo satisfactorio ${ }^{22}$.

Si se entiende por «secularización», como hace Blumenberg, una serie de transformaciones donde lo posterior sólo sería posible y comprensible presuponiendo lo anterior, que le fue dado de antemano, es el caso que aquellos que proceden a una explicación de la Modernidad como resultado de un proceso de secularización, paradójicamente, son incapaces de vivir, en razón de su propia explicación, en la época de la que pretenden dar cuenta. Si puede hablarse de «secularización» ocurre que se continúa inmerso en dicho proceso y por tanto en condiciones de seguir entendiendo aquello que le precedió: los elementos de una «nomundaneidad» (Unweltlichkeit) -tales como la esperanza, la salvación, la trascendencia o el Juicio de Dios- que el término, en el sentido antes referido, presupone. Su capacidad explicativa, por lo tanto, resulta ser nula. La explicación histórica del origen de la Modernidad mediante el concepto de «secularización» no es capaz de hacerse cargo de la Edad Moderna como resultado final de un proceso tal en tanto en cuanto la comprensión de la categoría en

22 Cf. LEM, 13-23.

Daimon. Revista Internacional de Filosofía, $\mathrm{n}^{\circ}$ 65, 2015 
cuestión necesita de un elemento teológico cuya pervivencia en la época moderna en aquel sentido, niega, bien lo moderno mismo, bien la propia explicación.

«Secularización» alude, según Blumenberg, a la existencia de un vínculo histórico entre las diferentes épocas que se suceden y que, en su sucederse, no se diluyen unas en otras, sino que se transforman: cada una de ellas es el resultado de aquella que la precede inmediatamente. Frente a «secularización» como «disolución» (Auflösung), el filósofo de Lübeck prefiere hablar de «secularización» como «conversión» (Umbildung) o «transformación» (Verwandlung) ${ }^{23}$. La diferencia, empero, no parece tan crucial y, de hecho, la idea de secularización como disolución y no como transformación de la teología puede incluso representar la expresión más extrema y radical, contra las pretensiones de Blumenberg, del teorema de la secularización ${ }^{24}$. Más interesante sería acaso oponer a «secularización» como «transformación», «secularización» como «liquidación» de la herencia teológica cristiana, es decir, como auténtica emancipación de la religión. En este sentido, la dilatación filosófico-histórica del significado de «secularización» guardaría una mayor afinidad con el sentido originario del término y con su aplicación jurídico-política. Su carácter metafórico se vería mermado hasta el punto de no poner en cuestión tan seriamente la legitimidad de la Edad Moderna ${ }^{25}$.

La crítica de Blumenberg al concepto de «secularización»se centra sin embargo en su interpretación como transferencia, y no erradicación, de contenidos religiosos. En este sentido, la secularización implica necesariamente el establecimiento de una identidad sustancial entre lo potencialmente secularizable y lo efectivamente secularizado y, de este modo, la afirmación de una continuidad histórica entre lo pasado y lo presente, que en consecuencia sólo ideológicamente caben ser radicalmente distinguidos ${ }^{26}$. Sin embargo, el propósito del estudio del filósofo de Lübeck no es otro que precisamente proceder a presentar la Modernidad como legítima por sí misma y no necesitada, pues, de legitimación externa alguna. Esta defensa blumenberguiana de la legitimidad de la Edad Moderna no pasa, empero, por reivindicar explícitamente la validez del teorema de la secularización como liquidación de la herencia teológica medieval, sino por oponer una interpretación funcionalista a la dominante concepción substancialista de la cuestión. De este modo, la Modernidad aparecería hipotecada teológicamente, ya no en su sustancia sino, en todo caso, en sus problemas ${ }^{27}$. La tesis del filósofo de Lübeck en relación a la secularización se cifra, en definitiva, en la afirmación de la validez funcional del teorema de la secularización, así como en la negación de su capacidad explicativa desde una perspectiva sustancial ${ }^{28}$.

La funcionalización blumenberguiana del teorema de la secularización, a la par que delimita su rendimiento teórico, justifica su uso y, al mismo tiempo, alivia la carga de ilegitimidad que incorporaría para la Modernidad ${ }^{29}$. Ahora bien, si «secularización» mienta

23 Cf. LEM, 24.

$24 \mathrm{Tal}$, el caso de la teología dialéctica. Cf. Marramao, G., Cielo y tierra. Genealogía de la secularización, trad. de P. M. García Fraile, Barcelona, Paidós, 1998, p. 110.

25 Cf. Monod, J. C., La querelle de la sécularisation. Théologie politique et philosophies de l'histoire de Hegel à Blumenberg, Paris, Vrin, 2002, pp. 24-30 y Rivera García, A., «La secularización después de Blumenberg», Res publica (Murcia), $\mathrm{n}^{\circ} 11-12,2003$, pp. 95 ss.

26 Cf. LEM, 32.

27 Cf. LEM, 56.

28 Cf. LEM, 70.

29 Cf. Galindo Hervás, A., «Los fundamentos teológicos de la política moderna», loc. cit., p. 59. 
sencillamente la estructura de un cambio de papeles entre la teología cristiana medieval y la filosofía moderna, entonces dicha transferencia de funciones deja de estar necesariamente vinculada a la estructura espiritual moderna, toda vez que una asunción de funciones análoga a la efectuada por la Modernidad fue llevada a cabo por la propia patrística medieval en relación a la filosofía antigua ${ }^{30}$. Entre la Antigüedad y la Edad Media existiría en fin la misma relación de continuidad funcional y discontinuidad sustancial que entre el Medioevo y la Edad Moderna. La singularidad de la Modernidad no radica según Blumenberg en ser el resultado de un proceso de secularización sino en la secularidad de las respuestas que ella ofrece a los interrogantes y problemas medievales heredados -en el hecho de que su posición frente a las preguntas no resueltas por la teología medieval no comporta recurso alguno a la trascendencia sino que permanece, o trata de permanecer, en los mundanales límites de una racionalidad autónoma, es decir, legítima por sí misma-.

La crítica de Blumenberg a la teología política de Schmitt tiene que ver así más bien con la retórica inherente a la analogía schmittiana entre los conceptos teológicos y jurídicopolíticos a la que, según el autor de La legitimidad de la Edad Moderna, se reduce la tesis sobre la secularización presentada en Teología política. Si el teorema de la secularización, según Blumenberg, alude simplemente a un mero reparto de funciones entre la teología y la filosofía, ello no obsta para que la esfera del lenguaje de lo sagrado haya sobrevivido a la de las cosas sagradas, ya secularizadas, conservándose como metáfora que opera a modo de coartada para legitimar ciertas novedades, tanto en el ámbito filosófico como en el científico y, quizá primordialmente, en el político. Aplicado al concepto central de la esfera jurídico-política, «soberanía», la persistente valoración positiva de la esfera de lo religioso que presupone el Säkularisationstheorem en sentido substancialista se pone de manifiesto por medio de una efectista voluntad de estilo que trata de ofrecer un fundamento a sus argumentaciones a través de la referencia constante a lo divino. La exageración es tal que, independientemente del valor explicativo, acaso pedagógico, que la metáfora pueda tener, puede conducir a la confusión entre lo metafórico y lo literal ${ }^{31}$.

Blumenberg encuentra en Teología política el paradigma de este fenómeno. Particularmente, en la analogía schmittiana entre la omnipotencia divina y la de un legislador concebido como legibus solutus ${ }^{32}$. Lo hiperbólico de la exposición schmittiana, según Blumenberg, invierte el sentido de su tesis sobre la secularización. Si Schmitt afirma que todos los conceptos centrales de la moderna teoría del Estado son conceptos teológicos secularizados, en realidad, según Blumenberg, el efecto de su argumentación es más bien el de establecer entre lo teológico y lo político una relación inversa, interpretando la reminiscencia teológica de los conceptos políticos como la consecuencia del carácter absoluto de éstos, es decir, procediendo a una teologización de la política, presionado quizá por el contexto político de su época ${ }^{33}$.

Según el análisis de Blumenberg, por lo tanto, Schmitt no concebiría realmente la teoría política moderna como el resultado de una secularización de ciertos conceptos teológicos, sino que habría llevado a cabo una teologización de una concepción profana de por sí de la

30 Cf. LEM, 74.

31 Cf. LEM, 81 ss.

32 Cf. LEM, 103 y TP, 37.

33 Cf. LEM, 91 ss.

Daimon. Revista Internacional de Filosofía, $\mathrm{n}^{\circ}$ 65, 2015 
soberanía como consecuencia de su preocupación por hacer comprensibles las exigencias políticas de su tiempo y, de ese modo, justificar la necesidad de reconsiderar la relación entre norma y excepción. El recurso schmittiano a las analogías teológicas habría servido así para legitimar la decisión sobre el estado de excepción que el pensamiento ilustrado y, en su época, el neokantismo de la teoría pura del derecho de H. Kelsen, rechazan radicalmente. Aunque cupiese interpretar la situación de la Alemania de la República de Weimar como un fracaso más, junto al de 1789, de la Ilustración, ello no justificaría, según la crítica blumenberguiana, recurso alguno a categorías anteriores a la Aufklärung, presentadas ahora como el resultado de un proceso de secularización, salvo el estrictamente metafórico. Según Blumenberg, por lo tanto, el problema de la retórica teológico-política empleada por Schmitt para legitimar su concepción de la soberanía surge cuando se olvida que la metáfora no es más que una metáfora y se la toma por la cosa misma, es decir, cuando se la legitima como concepto. Lo que para Schmitt es un concepto, para el filósofo de Lübeck es una mera metáfora incapaz en cuanto tal de ser fuente alguna de la legitimidad prometida y, en realidad, inventada.

\section{El «Epílogo» de Teología política II}

Si la liquidación petersoniana del vínculo entre lo teológico y lo político se limitaba a procurar su negación teológica, en su brevísima respuesta a La legitimidad de la Edad Moderna, Schmitt caracterizó la crítica blumenberguiana de la teología política como su negación científica ${ }^{34}$. Así, del mismo modo que su respuesta a Peterson consistió en denunciar el carácter absoluto de su trinitarismo, en relación a la crítica de Blumenberg la posición de Schmitt se apoya en una denuncia de las pretensiones absolutistas del cientificismo moderno defendido por su crítico: el auto-apoderamiento (Selbstermächtigung) y la deificatio de un hombre y un saber, el científico, que no necesitan de legitimación alguna, ya que se legitiman a sí mismos por su propio proceder. Si Blumenberg había denunciado el absolutismo teológico que a su juicio escondía el teorema schmittiano de la secularización, Schmitt hará lo propio con el absolutismo científico en que a sus ojos encuentra sus cimientos la crítica blumenberguiana. De este modo, Blumenberg hablaría, en opinión de Schmitt, el violento lenguaje de la filosofía de los valores que, por su justificación de la aniquilación de lo que no tiene valor (Unwert) desde su propia escala de valores, fue tan denostada por el jurista ${ }^{35}$. Uno de los primeros enemigos a exterminar por el deificado hombre moderno blumenberguiano era el teólogo político. Su disciplina no era ciencia sino, desde el punto de vista de ésta, mera metáfora: una perversa leyenda que debía ser desenmascarada y aniquilada, negada absolutamente como tal.

$\mathrm{Al}$ igual que en el caso de Peterson, la defensa de Schmitt frente a la negación cientificista de la teología política, que reduce ésta a mera retórica, consistirá en una reivindicación

34 Cf. TPII, 123 ss., Rühle, V., «La teología política a la sombra del nihilismo», en: V. Rocco - R. Navarrete (eds.), Teología y teonomía de la política, Abada, Madrid, 2012, pp. 133-146 y Villacañas Berlanga, J. L., «La leyenda de la liquidación de la teología política», en: TP, 173 ss.

35 Cf. Schmitt, C., «La tiranía de los valores», en: Herrero, M. (ed.), La tiranía de los valores, trad. de A. Schmitt, Granada, Comares, 2010, pp. 33-50 y Herrero, M., «Los valores o la posición absoluta de lo no absoluto», en: Id. (ed.), La tiranía de los valores, op . cit., pp. 5-32. 
de su carácter, precisamente, científico, conceptual o, mejor, histórico-conceptual, que el autismo de una Modernidad encerrada absolutamente en sí misma es incapaz de comprender satisfactoriamente. En su desmesurado afán por lo novum, la tesis blumenberguiana de una autofundamentación de la ciencia que brota de la nada desatiende necesariamente el umbral entre el Medioevo y la Modernidad en el que Schmitt sitúa el origen de la moderna teoría del Estado como el resultado de una secularización de categorías teológicas, esto es, de una sustitución de los teólogos por los juristas permitida, a su vez, por la simetría entre las estructuras e instituciones eclesiástica y estatal de la época, y cuyo resultado fue el silenciamiento político de los teólogos. El «yo soy jurista y no teólogo» de Schmitt vale tanto para Peterson como para Blumenberg. Ni uno ni otro supieron, quisieron o pudieron ver el carácter estrictamente jurídico-político -ni teológico ni metafórico- de la tesis schmittiana sobre la secularización.

\section{Conclusiones}

La distinción schmittiana entre los diversos sentidos de «teología política» permite superar tanto las objeciones de Peterson como las de Blumenberg, es decir, tanto la liquidación teológica como la negación científica del vínculo moderno entre la teología y la política que defiende la tesis schmittiana sobre la secularización, al menos si ésta es leída stricto sensu y no metafóricamente. Entendida desde un punto de vista histórico-conceptual, la teología política a la que se refiere Schmitt en su obra homónima es un fenómeno típicamente moderno, desprovisto de toda rémora teológica. Si el jurista hace uso de conceptos teológicos lo hace asumiendo la secularización en su radicalidad o, mejor, la secularidad constitutiva de la Modernidad. La teología política de Schmitt presupone la muerte de Dios, es decir, la desteologización del pensamiento, un mundo secularizado, privado de toda relación con la trascendencia, en el que el soberano asume el papel que antaño cumplió el Dios de los teólogos: ofrecer una garantía, ahora inmanente, del orden del mundo. También Schmitt, como Blumenberg, interpretaría la secularización, por lo tanto, en sentido funcionalista: el soberano schmittiano no es Dios desde el punto de vista de la sustancia, sino de su cometido. La relación analógica a la que se refiere $\mathrm{Schmitt} \mathrm{es} \mathrm{puramente} \mathrm{retórica,} \mathrm{pero} \mathrm{no} \mathrm{en} \mathrm{sentido}$ blumenberguiano: para el jurista lo importante no era legitimar teológicamente (dogmáticamente) su doctrina de la soberanía sino mostrar cómo ésta se hace cargo de aquella tarea que Dios, desaparecido del mundo moderno, no puede ya asumir más que ilegítimamente. El modo en que el Souverän de Schmitt lleva a cabo dicha labor se cifra en las dos categorías fundamentales de su teoría de la soberanía: los conceptos de representación (Repräsentation) y decisión (Entscheidung) ${ }^{36}$.

A la falta de fundamento de lo real que caracteriza a la Edad Moderna debe replicar en el plano político, según Schmitt, no una legalidad racional fantasmalmente fundada en sí misma y, en esa misma medida, desprovista de fondo, sino una legalidad (norma) legitimada por una decisión tomada por la voluntad, no en función de un orden eterno que la precede quiméricamente (el ius divino-naturale que determina sustancialmente las decisiones toma-

36 Cf. Galli, C., La mirada de Jano. Ensayos sobre Carl Schmitt, trad. de M. J. de Ruschi, Buenos Aires, FCE, 2010, pp. 19-96. 
das por el Pontifex Maximus como infalible intérprete de la revelación), sino sobre aquello que efectivamente está antes que ella: la más absoluta falta de orden (excepción). La esencia de la existencia política moderna (la soberanía) se cifra así, de acuerdo con la teología política schmittiana, tanto en el ser representado como en el ser decidido aquello que ha de ser representado, es decir, en un decidirse por aquello que ha de ser representado o una decisión para la representación que no puede decidir a partir de nada, sino sobre la nada: el desorden contra el que la soberanía está llamada a combatir mediante la representación, esto es, la realización de un sistema normativo que, carente de toda sustancia fundante premoderna, permite no obstante ordenar racionalmente la existencia de un pueblo, irracional qua existencia, y así darle forma (jurídica) como unidad política. He aquí la diferencia entre Soberanía y Papado, entre Estado e Iglesia, así como la razón de ser de la definición schmittiana del primero de los conceptos ${ }^{37}$. Al soberano no le basta con representar porque, para poder hacerlo, debe antes, necesariamente, decidir qué orden representar. Este contenido no le viene ya dado desde arriba ni por sí mismo, de manera evidente. Su representación no lo es de una verdad trascendente ni racionalmente autofundada sino que, conforme a la especificidad de lo moderno -su secularidad intrínseca-, no aspira a ser más que representación en sentido existencial ${ }^{38}$.

37 Cf. TP, 13.

38 Cf. Schmitt, C., Teoría de la constitución, trad. de F. de Ayala, Madrid, Alianza, 1982, pp. 205-209 y Voegelin, E., La nueva ciencia de la política. Una introducción, trad. de J. Ibarburu, Buenos Aires, Katz, 2006, pp. 41-96. He desarrollado la cuestión de la relación entre representación y decisión en el doctrina schmittiana de la soberanía en el artículo «Carl Schmitt y el pensamiento del orden concreto. Una crítica de la interpretación decisionista de la teología política schmittiana», Isegoría. Revista de Filosofía Moral y Política (Madrid), n 52 , enero-junio, 2015, pp. 349-364. 
